doeqtr.Dec.doc/sc-zip

DoE/PC/92543--T/5

DOE/PC: DE-FG22-92PC92543

\title{
MICRO-AGGLOMERATE FLOTATION FOR DEEP CLEANING OF COAL
}

Quarterly Progress Report: July 1 - September 30, 1996

by

S. Chander

R. Hogg

December 1996

Work Performed Under Contract No.

DE-FG22-92PC92543

For

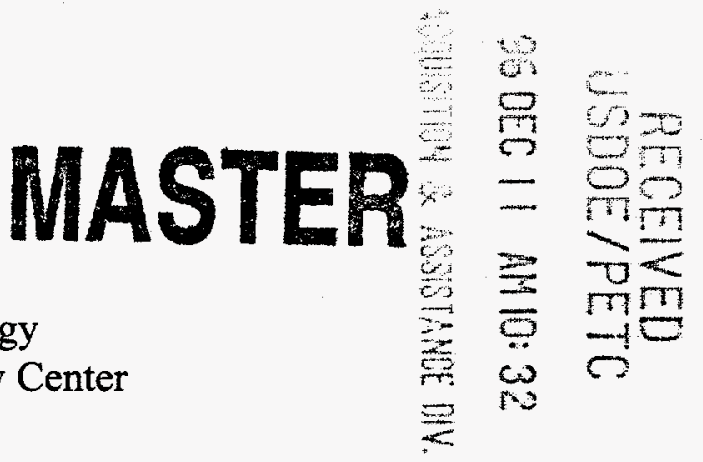

U.S. Department of Energy

Pittsburgh Energy Technology Center

Pittsburgh, PA

by

Penn State University

University Park, PA 16802

Detraburn of ThS Doovmentis

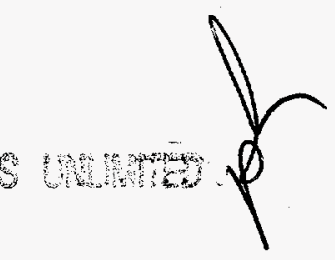




\section{DISCLAMMER}

Portions of this document may be illegible in electronic image products. Images are produced from the best available original document. 


\section{OBJECTIVES}

The goals of this research program are to demonstrate the technical and economic feasibility of a micro-agglomerate flotation process and to establish the essential criteria for reagent selection and system design and operation.

\section{Introduction}

The development of practical technologies for the deep cleaning of coal has been seriously hampered by the problems of carrying out efficient coal/mineral separations at the very fine sizes (often finer than $10 \mathrm{~mm}$ ) needed to achieve adequate liberation of the mineral matter from the coal matrix. It is generally recognized that surface-based separation processes such as froth flotation or selective agglomeration offer considerable potential for such applications but there remain many problems in obtaining the required selectivity with acceptable recovery of combustible matter. In froth flotation, selectivity is substantially reduced at fine sizes due, primarily, to overloading of the froth phase which leads to excessive carryover of water and entrained mineral matter. Oil agglomeration, on the other hand, can provide good selectivity at low levels of oil addition but the agglomerates tend to be too fragile for separation by the screening methods normally used. The addition of larger amounts of oil can yield large, strong agglomerates which are easily separated but the selectivity is reduced and reagent costs can become excessive.

We are investigating the use of a hybrid process - Micro-agglomerate flotation which is a combination of oil-agglomeration and froth flotation. The basic concept is to use small quantities of oil to promote the formation of dense micro-agglomerates with 
minimal entrapment of water and mineral particles, and to use froth flotation to extract these micro-agglomerates from the water/dispersed-mineral phase. Since the floating units are agglomerates (about 30-50 $\mathrm{mm}$ in size) rather than individual coal particles (1$10 \mathrm{~mm}$ ) the problems of froth overload and water/mineral carryover should be significantly alleviated.

Micro-agglomerate flotation has considerable potential for the practical deep cleaning of coal on a commercial scale. In principle, it should be possible to achieve both high selectivity and high yield at reasonable cost. The process requires only conventional, off-the-shelf equipment and reagent usage (oil, surfactants, etc.) should be small. There are, however, complications. The process involves at least five phases: two or more solids (coal and mineral), two liquids (oil and water) and one gas (air). It is necessary to maintain precise control over the chemistry of the liquid phases in order to promote the interfacial reactions and interactions between phases necessary to ensure selectivity. Kinetics as well as thermodynamic factors may be critical in determining overall system response.

The research program has been organized into several specific tasks as indicated below.

\section{Task 1. Interfacial Studies}

In order to provide a rational basis for reagent selection, fundamental studies of the various interfaces involved in Micro-Agglomerate Flotation are being conducted. In particular, data are being obtained on: 
- liquid/air and liquid/liquid interfacial tensions for aqueous solution/hydrocarbon systems.

- solid/liquid/air and solid/liquid/liquid contact angles for coals and important minerals (quartz, pyrite, etc.).

\section{Task 2. Emulsification}

The emulsification of oil in the presence of fine particles plays a critical role in the development of micro-agglomerate properties and in the rejection of pyritic sulfur and ash during agglomerate formation. The process is being investigated by measurement of emulsion droplet size distributions in agitated vessels of standard design. The effects of:

- coal type (especially hydrophobicity)

- surfactant type and concentration

- hydrodynamics

are of particular concern.

\section{Task 3. Agglomerate Growth and Structure}

In order to achieve the degree of selectivity required for effective deep cleaning of fine coal it is desirable to produce agglomerates which are large enough to be separated from the dispersed, refuse material and have sufficiently high density to minimize the inclusion of water and dispersed mineral particles. Studies of size/density relationships for oil-agglomerated fine coal are an important part of the 
research program. The role of hydrodynamics in agglomerate densification is of particular interest.

\section{Task 4 - Agglomerate Flotation}

The final separation of selectively aggregated fine coal particles from mineral matter is to be achieved using froth flotation. Standard procedures for flotation testing are being used to evaluate the floatability of micro-agglomerates formed under various conditions. Specific studies being carried out include determination of the effects of micro-agglomerate size and structure on the kinetics of flotation and evaluation of the potential for further cleaning of the floated material in multi-stage flotation circuits.

\section{PROJECT STATUS}

Research on the micro-agglomerate flotation process is essentially complete. A limited number of tests were conducted with column flotation using ultra-fine coal. Although the tests were as anticipated in absence of dodecane collector, the column showed unsteady state behavior in the presence of dodecane. These results confirm the complex behavior of the system. We have also performed additional tests under Tasks 3 and 4 to confirm our hypothesis that the age of the oil-water emulsion affects the kinetics of agglomerate growth and flotation performance. The results of these tests are being analyzed and will be submitted as part of the final report which is being prepared. 


\section{DISCLAIMER}

This report was prepared as an account of work sponsored by an agency of the United States Government. Neither the United States Government nor any agency thereof, nor any of their employees, make any warranty, express or implied, or assumes any legal liability or responsibility for the accuracy, completeness, or usefulness of any information, apparatus, product, or process disclosed, or represents that its use would not infringe privately owned rights. Reference herein to any specific commercial product, process, or service by trade name, trademark, manufacturer, or otherwise does not necessarily constitute or imply its endorsement, recommendation, or favoring by the United States Government or any agency thereof. The views and opinions of authors expressed herein do not necessarily state or reflect those of the United States Government or any agency thereof. 